\title{
Mediastinal Extension of Pancreatic Pseudocyst - A Case Report
}

\author{
Pratapsingh Hanumantsingh Parihar ${ }^{1}$, Sharvari Shashikant Gulve ${ }^{2}$
}

1, 2 Department of Radiology, Jawaharlal Nehru Medical College, Sawangi (Meghe) Wardha, Maharashtra, India.

\section{INTRODUCTION}

Pseudocyst is the common sequelae of acute and chronic pancreatitis. We present a case of mediastinal extension of pseudocyst, which is a rare entity. Pseudocysts are thick-walled fluid filled oval to round collections, located in pancreatic or peripancreatic bed. They can extend into mediastinum through diaphragmatic hiatus which is a rare entity.

\section{PRESENTATION OF CASE}

A 49-year-old male presented with pain in abdomen since 15 days with loose black coloured stools. There was no history of fever and vomiting. Patient was chronic alcoholic for past 30 years. He was also a known case of hypertension and diabetes. Complete blood count was done which revealed low haemoglobin. Further investigations revealed raised lipase levels. Then the contrast enhanced computed tomography scan of patient was done. It revealed small shrunken pancreas with dilated main pancreatic duct (approximate diameter of $4 \mathrm{~mm}$ ) Figure 1.

There was history of heterogeneously enhancing cystic lesion in the head of pancreas approximately measuring $4.5 \times 3.5 \times 3 \mathrm{cms}$ (Figure 2). This lesion is showing communication with cyst lesion in para-oesophageal recess. The cystic mediastinal lesion approximately measures $6 \times 5.2 \times 4.3 \mathrm{~cm}$ Figure 3 and Figure 4.

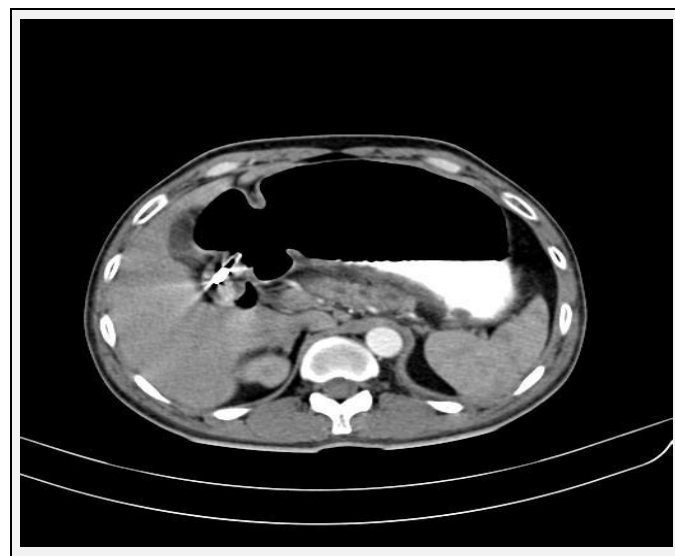

Figure 1.

Small and Shrunken Pancreas with

Prominent Pancreatic Duct
Corresponding Author:

Dr. Sharvari Shashikant Gulve,

Department of Radiology,

Jawaharlal Nehru Medical College,

Sawangi (Meghe), Wardha,

Maharashtra, India.

E-mail: sharvari23@yahoo.com

DOI: $10.14260 /$ jemds $/ 2021 / 70$

How to Cite This Article:

Parihar PH, Gulve SS. Mediastinal extension of pancreatic pseudocyst - a case report. J Evolution Med Dent Sci 2021;10(05):316318, DOI: $10.14260 / \mathrm{jemds} / 2021 / 70$

Submission 11-09-2020,

Peer Review 04-12-2020,

Acceptance 08-12-2020,

Published 01-02-2021.

Copyright (C) 2021 Pratapsingh Hanumantsingh Parihar et al. This is an open access article distributed under Creative Commons Attribution License [Attribution 4.0 International (CC BY 4.0)] 

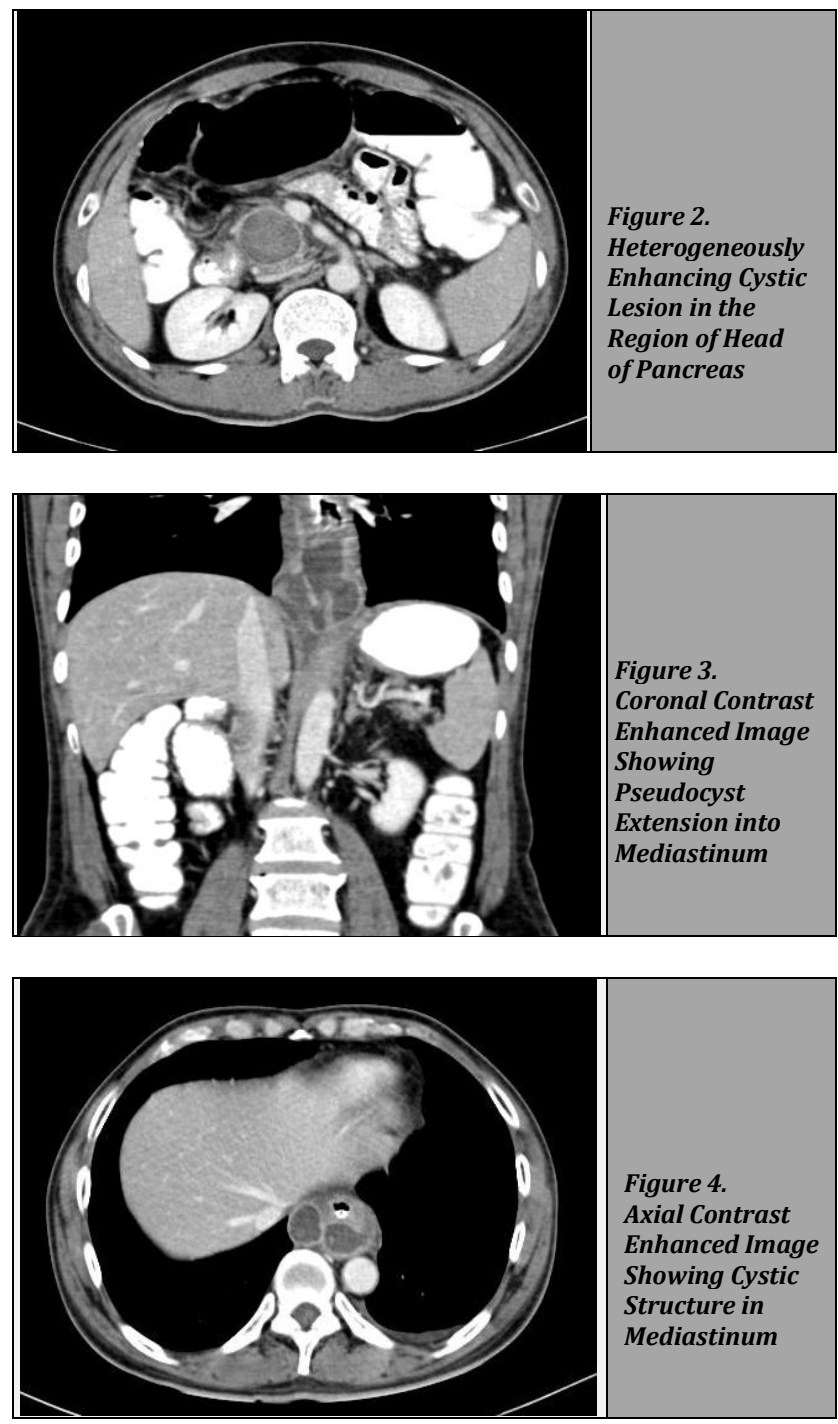

DISCUSSION

Pancreatic pseudocysts consist of pancreatic secretions enclosed in fibrous tissue (true cyst has epithelial lining). ${ }^{1}$ Pancreatic pseudocyst is a common complication of pancreatitis and is commonly seen in chronic pancreatitis. Pancreatic pseudocyst are seen in peripancreatic region but rarely seen in atypical location like spleen, kidney, liver and mediastinum etc. ${ }^{2}$ These pseudocysts can occur in age group of 7 months till 73 years, with leading cause in adults being alcoholic pancreatitis and in children being trauma. ${ }^{3}$

The growing pseudocyst extends along the plane of least resistance through anatomical passages such as aortic or oesophageal hiatus. ${ }^{4}$ Mediastinal extension of pseudocyst is rare. It occurs due to the rupture of pancreatic duct posteriorly and release of proteolytic enzymes into retroperitoneum. These enzymes dissect the diaphragm through hiatus. ${ }^{1}$ Contrast enhanced computed tomography (CT) scan has high sensitivity in providing location and anatomical relation of pseudocyst.

On CT scan, it appears as cystic low attenuation masses. In case of infection or haemorrhage, it appears hyperattenuating. Mediastinal pseudocyst can erode into pericardial sac causing cardiac tamponade or in pleural space causing pleural effusion ${ }^{2-5}$

The treatment generally consists of laparotomy or radiologically guided external drainage or endoscopically guided internal drainage. ${ }^{2}$ However, complications associated are many. ${ }^{3}$ Conservative treatment with abstinence from alcohol and proper diet is indicated in all patients. Studies on pancreatic pseudocysts ${ }^{6-7}$ were reviewed. Swarnkar et al. reported a case of heterotopic subserosal pancreatic tissue in jejunum. ${ }^{8}$ Jajoo et al. reported about a rare case of pre-sternal bronchogenic cyst ${ }^{9}$ Singh et al. studied about association between gall bladder diameter and calculus in the cystic duct in gall stone diseases. ${ }^{10}$ Many conditions of abdominal region and adjacent structures needed radiological guidance for treatment as reported by Swarnkar et al.,11-12 Talwar et al.,13 Samad et al.,14 Lamture et al.,15-16 and Jindal et al. ${ }^{17}$

\section{CONCLUSIONS}

Pancreatic pseudocyst extension into mediastinum is a rare entity which can present with cardiothoracic or gastrointestinal symptoms. Clinical symptoms, contrast enhance CT scan and serum lipase level can lead to accurate diagnosis. The correct diagnosis is important for surgical planning and treatment.

Financial or other competing interests: None.

Disclosure forms provided by the authors are available with the full text of this article at jemds.com.

\section{REFERENCES}

[1] Omer A, Engelman E, McClain J. Mediastinal extension of a pancreatic pseudocyst. Radiol Case Rep 2018;13(6):1192-4.

[2] Ravikanth R, Sarkar PS, Kale A. Mediastinal pseudocyst clinically presenting as mechanical dysphagia and dyspnea in a case of acute-on-chronic pancreatitis. J Curr Res Sci Med 2018;4(1):62-4.

[3] Karamouzos V, Karavias D, Siagris D, et al. Pancreatic mediastinal pseudocyst presenting as a posterior mediastinal mass with recurrent pleural effusions: a case report and review of the literature. J Med Case Rep 2015;9:110.

[4] Prasad BR, Paudel K. A rare case of pancreatic mediastinal pseudocyst. Kathmandu Univ Med J (KUMJ) 2007;5(3):408-11.

[5] Nasa M, Choudhary N, Patil G, et al. Mediastinal pancreatic pseudocyst. Journal of Digestive Endoscopy. 2016;7(1):20-3.

[6] Kim HC, Yang DM, Kim HJ, et al. Computed tomography appearances of various complications associated with pancreatic pseudocysts. Acta Radiol 2008;49(7):727-34.

[7] Segamalai D, Jameel ARA, Kannan N, et al. Mediastinal pseudocyst: varied presentations and managementexperience from a tertiary referral care centre in India. HPB Surg 2017;2017:5247626.

[8] Swarnkar M, Pandey P. Heterotopic subserosal pancreatic tissue in Jejunum. Formos J Surg 2018;51(4):167-70. 
[9] Jajoo S, Shukla S, Acharya S. Presternal bronchogenic cyst: a rare presentation. Indian J Med Spec 2019;10(2):105-7.

[10] Singh OH, Singh NS, Sarkar R, et al. Association between gall bladder diameter and calculus in the cystic duct in gall stone diseases and its importance in the current surgical practice- a cross-sectional study in JNIMS, Porompat, Manipur. J Evolution Med Dent Sci 2018;7(07):856-9.

[11] Swarnkar M, Agrawal A. Kimura's Disease. Formos J Surg 2018;51(1):26-8.

[12] Swarnkar M, Raghav J. Obstructed obturator hernia: a diagnostic dilemma. Journal of Krishna Institute of Medical Sciences University 2019;8(3):115-7.

[13] Talwar D, Kumar S, Andhale A, et al. Chilaiditi Syndrome, Unusual Complication of Rather Innocuous Abnormality: Case Report. Medical Science 2019;23(100):1011-14.
[14] Samad SA, Phatak SV. An Unusual Case of Abdominoscrotal Swelling in a Young Patient-Hydrocele En Bissac. Journal of Clinical and Diagnostic Research 2018;12(11):TD03-5.

[15] Lamture YR, Salunke B. Anatomical Variations Related to position of appendix. J Evolution Med Dent Sci 2018;7(46):5030-3.

[16] Lamture, Y, Varsha G. Migration of the coperitoneal shunt into a hernial sac. Journal of Clinical and Diagnostic Research 2019;13(11):PD01-2.

[17] Jindal R, Swarnkar M. Outcomes are local: a cross sectional patient specific study of risk factors for surgical site infections in major abdominal surgeries. Journal of Krishna Institute of Medical Sciences University 2020;9(1):43-50. 